\title{
Participatory action research in the age of social media: Literacies, affinity spaces and learning
}

\author{
Juan D. Machin-Mastromatteo ${ }^{1}$ \\ Institute of Information Studies, Tallinn University, Tallinn, Estonia
}

Originally published as: Machin-Mastromatteo, Juan D. (2012). Participatory action research in the age of social media: literacies, affinity spaces and learning, New Library World, 113 (11/12) pp. 571 - 585.

\begin{abstract}
This article is (c) Emerald Group Publishing and permission has been granted for this version to appear here (http://eprints.rclis.org). Emerald does not grant permission for this article to be further copied/distributed or hosted elsewhere without the express permission from Emerald Group Publishing Limited.
\end{abstract}

\begin{abstract}
PhD research about the integration of social media in higher education. Its aims are to determine significant issues, challenges and opportunities that emerge when social media are integrated into learning environments in higher education. 'Doing Online Relearning through Information Skills' (DORIS) is proposed as a research framework to address the aims, objectives, and research questions of this study. It was conceived from a Participatory Action Research perspective. This approach is intended to help discover and reflect upon teaching and learning practices in a technologically mediated educational setting. Furthermore, the concept of affinity spaces is discussed, together with its distinction from the concept of communities of practice. The data collection methods planned to conduct the study are: diagnostic questionnaire, blog, social learners' input and reports, a second questionnaire, and semi-structured interviews. The theory of affinity spaces offers a powerful way of thinking about teaching and learning processes mediated by different technologies. The heuristics that will focus the data collection and analysis are: a) on the function of content, and b) on the function of participants' interactions with the content and/or with one another. DORIS is proposed as a powerful way to organize learning interventions through the structure of information literacy skills. It is grounded on action research and on constructivist, blended, and problem based learning. Researchers, librarians or educators can adapt this model for teaching, learning and researching about and with social media or for other technologically mediated learning environments, or could be adapted for information literacy programs.
\end{abstract}

Keywords: social media, higher education, teaching, learning, participatory action research, literacies, information literacy, digital literacy, new literacies, affinity spaces.

Acknowledgements: I would like to acknowledge the valuable feedback and advice I received from Dr Russell James Francis and Dr Sirje Virkus.

\section{Introduction}

This article deals with the research design, methods and some of the concepts within an ongoing PhD research. Such research involves the integration of social media (SM) into higher education. Among others, the concept of affinity spaces is of paramount importance, it is used as an analytical lens and a framework to inform and discuss this research. Moreover, it is an alternative perspective to the concept of communities of practice. The distinctions between concepts and the usefulness of affinity spaces for this type of research are addressed within this article. Furthermore, the main

\footnotetext{
${ }^{1}$ Doctoral candidate in Information Science (Tallinn University), Master in Digital Library Learning (Oslo University College, Tallinn University, Parma University), and Bachelor in Library Science (Universidad Central de Venezuela). He has more than seven years of work experience in archives, libraries, and in higher education. He has excelled in different roles, such as: cataloguer, developing databases, library promotion materials and multimedia resources, as a reference librarian, supervisor, instructor, and collection development consultant. He has coordinated information literacy programs, written diverse articles published in open access repositories and in peer-reviewed journals, and presented in international high profile conferences such as ISKO and QQML. Author of the book Exploring users' information behavior in social networks: A contribution to the understanding of the use of social networks (2011).
} 
contribution of this paper is to take the theoretical idea of affinity spaces and propose a methodology to research empirically.

This $\mathrm{PhD}$ research is developed within the field of Library and Information Science (LIS), in the Institute of Information Studies of Tallinn University. Hence, the position of the researcher is that from a LIS background. However, this research is informed and driven by different theories, ideas and methods developed within other fields, such as education, management, philosophy and linguistics.

This $\mathrm{PhD}$ research is one of the logical extensions of the researcher's previous research (see Machin-Mastromatteo, 2011a and Machin-Mastromatteo, 2012). Some of its elements were taken and further developed for this current study within a learning setting. Currently, two studies have been planned; one of them as a pilot in 2011 and the final study will be conducted between late 2012 - early 2013. This paper centers mainly on the methodology planned for the final study, which is discussed in function of the theory of affinity spaces.

In order to conduct the study, a series of learning interventions and activities were planned according to the logic of Participatory Action Research. This approach is used to investigate teaching and learning practices in such a technologically mediated educational setting. This article provides a brief introduction to Participatory Action Research (section 2); introduces the aims, objectives, and research questions (section 3); describes the research design (section 4). Section 5 discusses the theory of affinity spaces as defined by Gee (2007) and examines its potential as an analytical lens that could guide data collection and analysis. Section 6 includes a brief account of the data collection methods and a description on how these methods will be used to collect the data about interactions among the participants of this study, as members of an affinity space.

\section{Participatory Action Research}

Whitehead and McNiff (2006) claim that in the 1930s, the beginnings of action research (AR), it "was seen as an applied social science" (p. 21). Most researchers within the field of AR locate its origin between the 1930s (Whitehead and McNiff, 2006) and 1940s. Kurt Lewin is often cited as one of the originators of this research tradition. He developed a comprehensive action research theory in the 1940s and defined the approach as: "a comparative research on the conditions and effects of various forms of social action and research leading to social action" (Lewin, 1946, p. 35). Lewin's works were located within an industrial setting and concerned itself with the ways workers' struggle to overcome their disadvantageous situations. In general, concerns with questions of power and/or discrimination against minority groups are recurrent themes in action researchers. Lewin's studies present some relevant notions, such as: knowledge generation from problem solving, group dynamics, intergroup relations, and the improvement of people's conditions for examining their realities.

Participatory Action Research (PAR) draws attention to the reactive effects due to the presence of the researcher has within a participatory community. Furthermore, PAR actively aims to facilitate change and improve practice. PAR is naturally a tradition within AR, they may be confused, and the differences between both traditions might be subtle or overlooked. However, PAR stresses the commitment of all participants to the goal of the study, they embark on a collaborative endeavor, meaning that the researcher works with the participants from his or her own knowledge and mediating a common understanding from their own knowledge, practices and realities. As Herr and 
Anderson (2005) stress it, "PAR tempers this expert knowledge with the expertise of locals [or participants] about their own problems and solutions" (pp. 9-10) According to McIntyre (2008) the aims of participatory action research "are achieved through a cyclical process of exploration, knowledge construction, and action at different moments throughout the research process" (p. 1). Similarly, McTaggart (1997) sees PAR as a living dialectical process, one that changes the researcher, the participants, and the situations or realities where they act. Freire's (1970) approach emphasizes the active participation of students and collapses the teacher-student dichotomy. As a result the teacher becomes the 'teacher-student' and learners become 'student-teachers'. Fals-Borda (1973) is also of relevance, from his incorporation of the community action into research plans.

\section{Aim, Objectives, and Research Questions}

The project aims to determine significant issues, challenges and opportunities that emerge when SM are integrated into learning environments in higher education. Learning, literacies, and social media (SM) are conceived as elements that mutually shape one another during the study. The main epistemological assumptions of this study are that knowledge is created through socialization (Vygotsky, 1978; Nonaka and Takeuchi, 1995) and can be discovered (Whitehead and McNiff, 2006), as people possess tacit knowledge within (Polanyi, 1958). Moreover, teachers are capable of generating personal theories by systematically studying their practice (Whitehead, 1989). In the following paragraphs, and prior to the research questions, the concepts of learning, literacies, and SM are briefly explained in the ways they are used within this research.

\subsection{Learning}

The conception of learning that is used throughout this research follows the learning theories of constructivism and social constructivism. Furthermore, learning is viewed as a three dimensional process that may occur at an individual and collective level as well as in many different environments and affinity spaces. According to Illeris (2003), learning has three dimensions: cognitive, emotional and social. The cognitive dimension "may be described as knowledge or skills and which builds up the understanding and the ability of the learner"; the emotional dimension encompasses "mental energy, feelings and motivations"; and the social dimension is the "external interaction such as participation, communication and co-operation" (p. 399).

\subsection{Literacies}

The concept 'literacies' is used as an umbrella term to group the concepts: 'information literacy' (Zurkowski, 1974; Virkus, 2003; Tuominen, Savolainen and Talja, 2005; Lau, 2006), 'digital literacy' (Shapiro and Hughes, 1996; Lankshear y Knobel, 2006), and 'new literacies' (Gee, 2001; Lankshear and Knobel, 2007; Lankshear and Knobel, 2011). The present researcher has been developing this categorization and the following concepts during the last two years (see Machin-Mastromatteo, 2011b; and Machin-Mastromatteo, 2012). Information literacy is broadly defined 
as the individual's ability to handle information in general. Digital literacy refers to the ability to handle technological devices (hardware and software). New literacies are a series of new and innovative skills associated to ways of working with online content and social technologies. Thus, going beyond the concept of digital literacy.

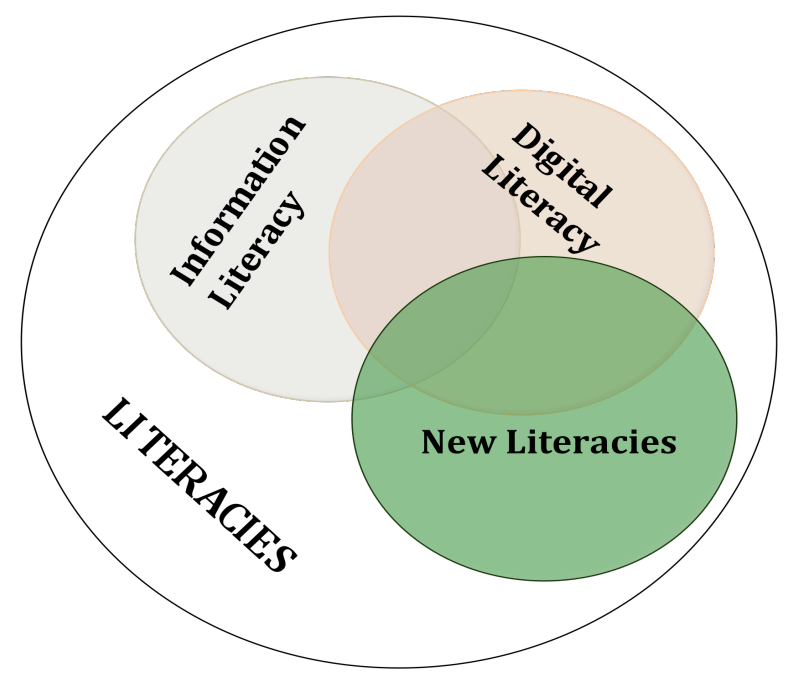

Figure 1. Articulation of literacy related concepts

Figure 1 above represents the articulation of literacy related concepts mentioned in the previous paragraph. The term literacies contains the other three concepts. Some ILs are translated to the digital world (ICTs). NLs are less intersected with IL and more with DL, as in their majority they imply the use of newer technologies, frameworks or workflows. Some NL might be the ones related to the content creation and curation using SM (as they might not be considered established skills). Obviously, DL and NL are related with one another because of technology, but at the same time, they would be somehow related to IL, as this technological side is related at the same time with the ICTs.

\subsection{Social Media}

The term social media (SM) is used to refer to "websites or software applications, which allow the publication or posting of user generated content and also the interactions between their users" (Machin-Mastromatteo, 2011a). Hence, it would include sites such as Facebook, Google+, Twitter, Tumblr, Pinterest, among others. Moreover, this concept would also include wikis and blogs. It is important to note that although most of these applications have been designed for entertainment, they have also being used for business and academic purposes (serious purposes). Hemmi et al. (2009) states that although "the academy appears to be 'appropriating' such technologies for pedagogical purposes" (p. 19), their pedagogical implications are not fully explored and not much formal research involving the integration of SM into higher education has been published. Naturally, in the last four years, this area of research has been increasing. Part of this increase of interest from the scientific community might be due to the fact that these technologies have been a buzz or a fad in the last five years (approximately), as well as their high acceptance and use. Moreover, they offer free, attractive, and easy to use alternatives to Virtual Learning Environments (VLEs). According to Hemmi et al. (2009) VLEs "are generally failing to engage with the rich potential of the digital environment for learning" (p. 20). VLEs' problems are mainly due to design issues, redundancy, and 
unsuccessful translations of old practices into the digital world. (Cousin 2005, Bayne 2008).

\subsection{Objectives and research questions}

Given the present theoretical stance regarding the concepts of learning, literacies and SM, the main objective of this project is to determine significant issues, challenges and opportunities that emerge when SM are integrated into learning environments. Secondary objectives aim to determine:

a) if students can learn and describe the kind of learning taking place through the integration of social media;

b) the role of literacies in students' engagement in learning activities;

c) the ways learning, literacies, and social media mutually shape one another.

To this end, the research is guided by the following main research question: What significant issues, challenges and opportunities emerge when social media are integrated into learning environments in higher education? Subquestions to this study are as follows:

a) How do students' experience learning when they are engaged in a learning activity that integrates social media?

b) In what ways is students' engagement dependent upon their literacies?

c) In what way do learning, literacies and social media mutually shape each other?

\section{Research Design}

The following section deals with the profile of the participants in this study and describes the research design, which is based in five stages. Three of these stages include an assignment the participants have to develop.

\subsection{Participants}

The study involved two groups of international students from LIS master courses. One group has already participated in the pilot study and another is expected to participate in the final study. Many participants from the pilot study were familiar with relevant LIS concepts like literacies, information needs and information practices. Other participants were not familiar with these topics because they do not have a LIS background but nevertheless are enrolled in the master program. Even so, most of them use social networks in their everyday practices and many were readily available for interview. The participants for the final study are being sought with a similar profile.

Among the changes and refinements done to the research methods and the further revision of useful theories for the final study, is the way participants are seen and called. The participants for the final study are labeled as 'social learners' throughout the rest of this paper. According to the logic of Participatory Action Research, the researcher is a participant as well. This is opposed to different paradigms, such as the positivist tradition, which demands the researcher to remain as the proverbial 'fly on the wall' during the study. The role of the researcher is to plan the learning interventions and the devices throughout the study. Furthermore, the position of the researcher is to participate, intervene and interact with the social learners. 
Moreover, the researcher prepares, explains and mediates themes and shared meanings, which is discussed in the next section. The researcher as a participant is labeled as 'lead social learner' throughout the rest of this paper. When referring to both the lead social learner and the social learners at the same time, and for the sake of brevity, the phrase 'all participants' is used.

\subsection{Research Design: Doing Online Relearning through Information Skills}

The research design for the final study is labeled as 'Doing Online Relearning through Information Skills' (DORIS). The word 'relearning' is used to denote the fact that the social learners are already SM users. Hence, they already know how to use these online technologies. However, social learners are expected to relearn how to use SM specifically for 'serious purposes'. They will be engaged in real world and problem-solving assignments, which should require them to use their information skills (access, evaluation and use) as they are described below. Apart from these information skills, which are related to information literacy, their digital literacy will play some roles in their engagement, successfulness and overall learning during the study. Moreover, new literacies are expected to emerge, to be rationalized and to define and redefine practices, skills and concepts that will be part of the results of this study. Furthermore, it is expected that this design, together with the data collection methods will bring enough participants' insights that will answer the research questions.

DORIS is comprised of different learning interventions, and it is divided in five stages. Figure 2 below indicates the sequence and contents of the different stages planned for DORIS. Each of them has a series of topics that all participants are to discuss in the classroom. Before each of the themes, the social learners discuss what they already know, think and believe. Then, the lead social learner explains the topics from that input, in order to mediate a mutual understanding of the topics. At the end of stages 1 to 4 , social learners are encouraged to discuss or comment on the blog created by the lead social learner both as a dialog space and content hub. It is important to note that these characteristics (content and interactions) of the blog make it an affinity space, as it is explained in section 5. After Stage 3 social learners have to create their own social sites. These sites are other spaces to dialog and discuss among all participants.

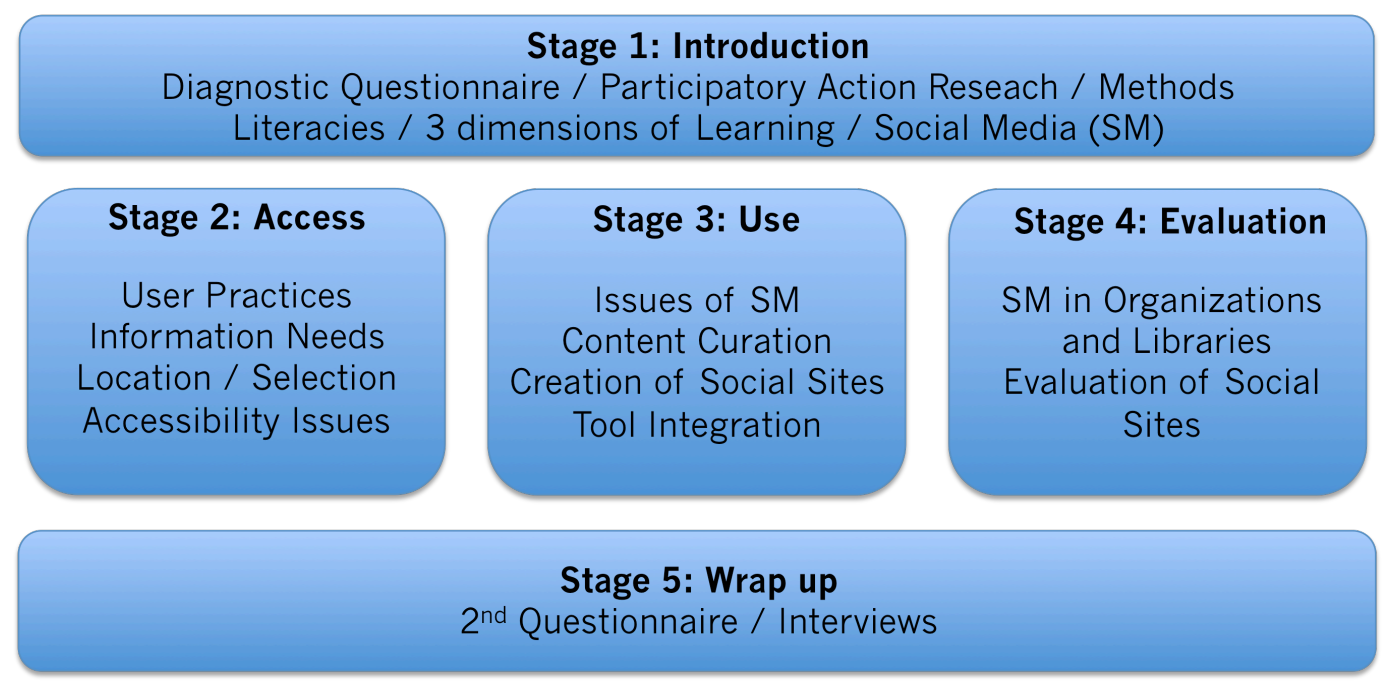

Figure 2. Research design 'Doing Online Relearning through Information Skills’ (DORIS) 
Stages 2 to 4 were thematically organized as core information skills. These skills are: access, use, and evaluation of information. These three information skills are understood as components or dimensions of information literacy. Lau (2006) states that these dimensions of information skills are commonly found in the works of different educators as Byerly, Brodie, and Kuhlthau. Furthermore, they appear in standards prepared by library associations, such as AASL, ACRL, SCONUL and the Australian and New Zealand Institute for Information Literacy. The concept of skills is used rather than competencies because skills are understood as sets of different and diverse 'ways to do things'. These sets may be known, learned, transferred, or unknown (created, developed, discovered). In the latter case, they would emerge from a research design such as DORIS. The core information skills are three, but the empirical study together with the analysis of the literature will determine subsets of skills. The concept of competences is not used because it might be understood as a set of defined behaviors, which are highly structured and predetermined. The term of competences may also be associated to 'the right way' to do things. Hence, competences would be related to different approaches or paradigms such as positivism, information behavior, and cognitive studies, which are far from a PAR perspective. The prominence of the core information skills may give the impression that information literacy is dominant in DORIS, but it is possible to think about digital literacy (DL) skills and new literacies (NL) skills in the function of these core information skills. Both DL and NL skills may be located within this categorization of access, use, and evaluation.

The results of the pilot study, which was conducted prior to the development of DORIS, pointed to the need for greater coherence and uniformity in the research design. The organization of DORIS addresses this by clustering the three main stages of the design after the core information skills. This provides a more effective framework for determining how social learners' literacies mediate their learning and engagement. The social learners may find different challenges and opportunities given how proficient they are regarding each core information skill. Hence, by clustering the research design in this manner, it will be possible to reflect on how an individual's proficiency on each skill can mediate or play other roles in learning and engagement.

Upon completion of stages 2 to 4, students have to do an assignment per stage. The first assignment is individual, and for the other two the social learners have to work in teams. These assignments are role-playing activities. These kinds of hands-on activities "can equalize the relationships between the literate and illiterate, between the marginalized and the self-confident" (Mikkelsen, 2001, p. 118.) Because "PAR is context specific means that practitioners draw on a variety of quantitative, qualitative, and creative-based methods to engage participants in the construction of knowledge" (McIntyre, 2008, p. 49).

The first assignment (for stage 2) involves an individual reflection about the social learner's practices as a user of SM. The second assignment (for stage 3) involves the creation of a SM site (social learners choose the tool they wish to use) for a fictional information service. The third assignment (for stage 4) is an evaluation of an existing SM site for an information service. For each assignment, the participants have to hand in a short written report. These assignments correspond to each core information skill, they are expected to develop relearning, cause learning dissonances, and make social learners rationalize, critically reflect upon, discuss, improve, develop or reinvent their practices as SM users, among other processes. These processes within DORIS are related to learning, literacies and social media. Hence, they are bound to bring the data 
necessary to answer the research questions. The following table summarizes the learning outcomes, themes and assignments as they appear in each stage of DORIS.

\begin{tabular}{|c|c|c|c|}
\hline Stage & Learning Outcomes & Themes & Assignment \\
\hline 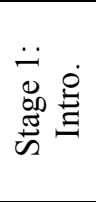 & $\begin{array}{l}\text { Understand the principles of a } \\
\text { participatory action research } \\
\text { learning intervention. }\end{array}$ & $\begin{array}{l}\text { Participatory Action } \\
\text { Research, Methods, } \\
\text { Literacies, } 3 \text { dimensions } \\
\text { of Learning, Social } \\
\text { Media. }\end{array}$ & N/A \\
\hline 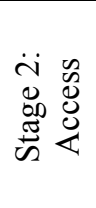 & $\begin{array}{l}\text { Reflect about my own practices as } \\
\text { a social media user and relate them } \\
\text { to other social learners' practices. }\end{array}$ & $\begin{array}{l}\text { User practices, } \\
\text { Information needs, } \\
\text { Location and selection, } \\
\text { Accessibility issues. }\end{array}$ & $\begin{array}{l}\text { Write a short report } \\
\text { reflecting on your practices } \\
\text { as a Social Media user, } \\
\text { taking into account insights } \\
\text { gained during the session. }\end{array}$ \\
\hline 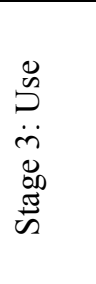 & $\begin{array}{l}\text { Reflect upon the issues of social } \\
\text { media, your literacies and how they } \\
\text { might affect your performance and } \\
\text { the learning. Understand how to } \\
\text { create a social media site, curate } \\
\text { content and to integrate different } \\
\text { tools }\end{array}$ & $\begin{array}{l}\text { Issues of social media, } \\
\text { Content curation, } \\
\text { Creation of social media } \\
\text { sites, Tool integration. }\end{array}$ & $\begin{array}{l}\text { Develop a social site for a } \\
\text { fictional information service } \\
\text { and present a short report } \\
\text { about what you did, and the } \\
\text { challenges and issues you } \\
\text { faced. }\end{array}$ \\
\hline 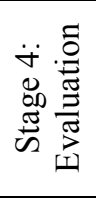 & $\begin{array}{l}\text { Understand how can a social media } \\
\text { site be evaluated. Reflect upon how } \\
\text { the discussed criteria for evaluation } \\
\text { might make you change the site } \\
\text { you already developed }\end{array}$ & $\begin{array}{l}\text { Use of social media in } \\
\text { organizations and } \\
\text { libraries, Evaluation } \\
\text { social media sites. }\end{array}$ & $\begin{array}{l}\text { Analyze and evaluate an } \\
\text { established social site for an } \\
\text { information service. Revisit } \\
\text { your second assignment } \\
\text { (your social site) and reflect. }\end{array}$ \\
\hline 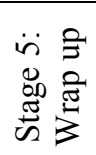 & $\begin{array}{l}\text { Reflect upon the research questions } \\
\text { and your experiences in this study }\end{array}$ & N/A & $\mathrm{N} / \mathrm{A}$ \\
\hline
\end{tabular}

Table 1 Stages, Learning Outcomes, Themes and Assignments during DORIS

\section{Affinity Spaces}

DORIS involves the participation and interactions of the lead social learner and the social learners within different spaces: the classroom, a blog, and SM sites. The description of the devices set up in this study, and the analysis of the data gathered are challenging issues. It is possible to simplify the elements of the research in two categories: content and interactions. On one side, the researcher as a practitioner, reflective teacher, and participant of the study sets up these spaces and devices, which are rich in content. The social learners have to deal with such content and then produce more content (their assignments and SM sites). The lead social learner interacts with the social learners by mediating the concepts and topics studied by both parties. Then, the social learners interact among themselves in order to develop their assignments. Finally, further interactions among all participants are encouraged through the blog at any stage of the research.

The theory of affinity spaces seeks to account for both content and interactions, central elements within the present research design, and typical features of devices 
such as blogs, SM sites and other technologies that may be used for learning purposes. Gee (2007) offers the concept of affinity spaces, as a conceptual tool for thinking about and researching learning. He highlights its importance for the future of schooling. Further, it offers a powerful way of thinking about teaching and learning processes mediated by different technologies, such as SM (blogs, wikis, Facebook, Twitter, among others) or videogames.

\subsection{The Use of Affinity Spaces Instead of Communities of Practice}

Gee (2007) is critical of the notion of a 'community of practice' (Lave and Wenger 1991, Wenger, 2006). For Wenger (2006), in a community of practice, membership "implies a commitment to the domain, and therefore a shared competence that distinguishes members from other people" (What are Communities of Practice section, para. 4). The notion of membership can mean many things in different degrees depending on the group in question. Hence, "it is not clear that membership is a truly helpful notion" (Gee, 2007, p. 88). An affinity space centers mainly on being a space for interaction, regardless of the fact that the people interacting have or not a membership within a community. It "focuses on the idea of a space in which people interact, rather than on membership in a community" (Gee, 2007, p. 87) or on their purposes. As a general rule, when membership is difficult to determine or contested, the ideas of communities of practice might not be useful. (E. Wenger, personal communication, April 10, 2012)

There is also the issue of purpose; something that characterizes communities of practice is the common endeavor among its members, implying a collective purpose. According to Wenger (2006) "[c]ommunities of practice are groups of people who share a concern or a passion for something they do and learn how to do it better as they interact regularly" (What are Communities of Practice section, para. 2). Smith (2009) highlights "[t]he fact that they are organizing around some particular area of knowledge and activity gives members a sense of joint enterprise and identity" (p. 3). However, in educational environments, every individual might have their own idea of their goals or purposes. Individuals control their own level of participation and engagement. So, the concept of common endeavor is not necessarily here.

Gee (2007) argues that it does not make sense to include two individuals with different purposes in the same community of practice just because they share the same space, or some practices. This involves the issue of having to specify how in or out of the community is every individual. For this reason, it makes little sense to label the social learners as a community of practice.

There are other particular elements in the concept of communities of practice that are incompatible with DORIS. These are related to continuity, the idea of newcomers and power relations.

The idea of continuity and relations over mid to long-term periods of time: "members are involved in a set of relationships over time" (Lave and Wenger 1991, p. 98). The community of practice generates and appropriates what Wenger calls a "shared repertoire of resources", and that "takes time and sustained interaction" (Wenger, 2006, What are Communities of Practice section, para. 6). DORIS has to be conducted in a few sessions. Hence, this time limitation prevents the participants to be a community of practice.

Lave and Wenger's (1991) idea of newcomers, as individuals becoming more competent and hence more involved in the community is absent from this research, as all participants start from the same point, and arguably their engagement could be a matter of choice or personality. 
According to Smith (2009): "there may situations where the community of practice is weak or exhibits power relationships that seriously inhibit entry and participation" (p. 5). Within the DORIS, power divides are likely to be weak. Thus complying with PAR and specifically with Freire's principles on this matter. It is not possible to deny entry and they can hardly impact participation. Rather, more experienced participants might foster less experienced ones. Furthermore, diversity in participants' skill is highly sought.

\subsection{Components of an Affinity Space}

Gee (2007) divides the components of an affinity space into: 'content', that is what the space is about; 'generators', which are the entities giving content to the space; and 'portals', which are the entities used for the people to enter the space, "gives access to the content and to ways of interacting with that content, by oneself or with other people" (Gee, 2007, p. 94). Portals can be physical as well as digital places. Also, a portal can be a generator, as long as people can add to or modify its content. Similarly, a generator can be a portal, as long as it is visible to the people interacting in the space. The components of an affinity space, as they are present within DORIS, are discussed below.

a) Content: all the participants produce content. The lead social learner produces the blog, its content deals with the topic of access, use and evaluation of SM, with full text or links. The social learners produce content for their SM sites and their reports. Content and interactions in the blog and SM sites are intertwined (see 5.4).

b) Generators: all participants are generators in the sense that they give content to the spaces. The blog and the social sites are not considered as generators. Although conceptually correct, they are seen as portal/generators (see below).

c) Portals/Generators: the blog and the SM sites are portals/generators. They are portals because they give participants access to the content and interactions. They are generators in the sense that all participants can add or modify its contents.

DORIS as a whole is an affinity space. However, the classroom, the blog, and SM sites are smaller affinity spaces within DORIS. These spaces have their own possibilities to organize content and interactions. Furthermore, different people might like one more than the others and draw different things from each. Thus, depending on the data gathered, it might be useful to consider all these spaces one at a time.

\subsection{Affinity Spaces as a Unit of Analysis}

As Gee (2007) states, "The notion of affinity spaces can lead us to ask some new questions about classroom learning or ask some old ones in new ways" (p. 90). Affinity spaces allow for two different dimensions or heuristics to focus the data collection, and drive data analysis at a later stage.

a) On the function of its content: this is an analysis of the content organization or design. In the case of blogs or other SM sites, the content organization and design emerges initially from whoever designed the space, but then its users (that is all participants in DORIS) shape it. 
b) On the function of how people interact with the content and/or with one another: this analysis points to the interactional organization, contextual and social interactions, and the organization of people's opinions, comments and actions.

It is challenging to distinguish between both dimensions when conducting this kind of research on SM. This is mainly due to the fact that the interactions in SM can be seen as part of the content. For example, in Facebook someone posts something and that is content, regardless of its nature and purpose. If someone comments on the post, this too becomes content, and it is interaction at the same time. However, for the purpose of clarity, content is what all participants create or aggregate: the blog, the SM sites and the reports. In consequence, interactions are the dialogs or participants' input that are registered over the content.

The next section describes the data collection methods. It provides some insights into how the previously stated heuristics are applied to collect data about content organization and interactions.

\section{Data Collection Methods}

The use of different methods allow for the triangulation of data obtained through each of them. Thus, achieving a comprehensive analysis of the interactions and experiences occurring along the study. The methods used for the collection of data are now discussed.

\section{a) Diagnostic Questionnaire}

A diagnostic questionnaire is used to determine how much the participants already use SM. It serves to get some insights on how they have used these technologies for learning purposes, either as teachers or students, before taking part in DORIS. It encouraged participants to comment on the ways SM could be useful for learning. Furthermore, it seeks to determine their understanding of the concepts information literacy and digital literacy, central to this research. The results of the diagnostic questionnaire do not directly indicate content or interactional issues. Rather, it serves as a profiling tool, to get to know more about the social learners. Moreover, it is an indication of the possible last minute adjustments to be made to the methods and depth of the themes to deal with in DORIS. The diagnostic questionnaire is divided in four sections: 'your use of social media', 'social media and learning', 'your experiences using social media for learning purposes', and 'the concepts of literacies'. Furthermore, it is the basis to determine tensions and dissonances present in the social learners' answers between the start of the study and by the end of it (with the second questionnaire). 
The blog is set up both as a dialog space and content hub. By default blogs are dialog spaces, and offer the possibility for its users to provide input on each of its sections. They enable and encourage dialog among all the participants and registering this kind of input with no additional effort. Thus, collecting interactional data. The blog as a content hub is a central and common space to gather the content and the activities to develop in DORIS. In consequence, it has content design and organization.

As an affinity space, the blog is a portal and a generator at the same time. As a portal, it gives access to the content. Moreover, it enables and encourages different dimensions of knowledge: tacit, explicit, individual, distributed, intensive, extensive, and dispersed. Additionally, the blog offers different routes to participation, meaning that all the participants can choose how much they comment on the forums, if they use the links provided, look for further readings or volunteer to have the interview for their team. As a generator, the blog allows for the addition and modification of its content.

\section{c) Social learners' input}

Social learners' input is important interactional data to be collected. It is a way of following their learning and impressions throughout the study. As well as the mediation and common understanding of the themes, together with tensions and dissonances emerging from the different stages of DORIS. Social learners' input was registered in:

- The classroom: each theme is discussed from the social learners' understanding (see section 4.2) and then mediated by the lead social learner to reach common understandings. These primary insights have to be registered as important data.

- In the Blog (see previous section)

- In the SM sites they created: the social learners have to develop social sites as one of the assignments, as social sites they enable and encourage interaction.

\section{d) Social learners' reports}

Social learners' reports contain a written semi-formal reflection about their work in the assignments after developing them. These reports are intended to be a brief account of the social learners' challenges, issues, interactions and the content they created or dealt with in the assignments. It is important to note that the reports are written from the teams' voice, which might exclude limitations or issues that individual social learners may have. This is a flaw that the individual questionnaires address.

\section{e) Second Questionnaire}

The second questionnaire serves for contrasting answers given to similar questions in both questionnaires, accounting for tensions and dissonances between social learners' answers. This questionnaire is divided in four sections: 'issues, challenges, and opportunities of social media', 'learning', 'literacies', and 'the mutual shaping'. 
Needless to say, these sections correspond respectively to each of the research questions.

\section{f) Semi-structured Interviews}

Semi-structured interviews are conducted with a member of each team. These are intended to expand on the questionnaires, in the sense that it is possible to gather more in depth data about how the students worked together, their challenges, issues, learning that took place. Both the second questionnaire and the interviews were conducted at the end of DORIS

\section{Conclusion}

This ongoing PhD research is framed within the Participatory Action Research paradigm. The use of this research method encourages the researcher to intervene, participating actively with the participants of the study. Moreover, this research tradition seeks to reduce power relations and oppression, such as with the Freirean conception of teachers as learners. That is why the researcher is been called the lead social learner and the participants are labeled as social learners.

This article contains theoretical considerations and a research design. A forthcoming article will include results from the empirical investigation conducted from the perspective and methods presented and discussed in the present article. In this paper, I have discussed the potential of using Gee's concept of an affinity spaces as an alternative unit of analysis for DORIS, instead of the more familiar 'communities of practice'. Moreover, the components of an affinity spaces were explored, by stating where they are present within DORIS. I have argued that affinity spaces offer a powerful way of thinking about teaching and learning processes mediated by different technologies, such as SM (blogs, wikis, Facebook, Twitter, among others). Furthermore, the heuristics taken from affinity spaces to focus the data collection and analysis are: a) on the function of its content, and b) on the function of how people interact with the content and/or with one another. The data collection methods are described in the light of these heuristics.

The main contribution from the discussions within this paper was to take the theoretical idea of affinity spaces and propose a methodology to research empirically. The conceptual level of Gee was moved to a methodological realm. This was achieved by translating the concepts and principles of affinity spaces to the terms of DORIS and its data collection methods. Furthermore, the heuristics highlighted guide and focus data collection and analysis. Moreover, the research design DORIS proposed in this article is a powerful way to organize learning interventions through the structure of information literacy skills. Such interventions are grounded in the action research paradigm and based on constructivist, blended (physical and online), and problem based learning. Other researchers, librarians or educators can adapt this model in order to develop learning interventions for learning and researching about and with SM or other technology mediated learning environments. Furthermore, DORIS framework can be adapted for teaching information literacy programs or other topics, by changing the themes discussed in the different stages. This could result in a powerful framework to teach different topics by going step by step through different information skills needed to research and use the information, resources or devices relative to different disciplines. 


\section{References}

Bayne, S. (2008). Higher education as a visual practice: Seeing through the virtual learning environment, Teaching in Higher Education 13, pp. 383-394.

Cousin, G. (2005). Learning from cyberspace. In R. Land and S. Bayne (Eds.), Education in Cyberspace, (pp. 117129). London: RoutledgeFalmer.

Fals-Borda, O. (1973). Reflexiones sobre la aplicación del método de estudio-acción en Colombia. Revista Mexicana de Sociología, 35 (1), pp. 49-62.

Freire, P. (1970). Pedagogy of the oppressed. New York: Continuum.

Gee, J. P. (2001). New Times and New Literacies: Themes for a Changing World. In Eighth International Literacy \& Education Research Network Conference on Learning (pp. 3-20). Presented at the Eighth International Literacy \& Education Research Network Conference on Learning, Spetses, Greece.

Gee, J.P. (2007). Good video games and good learning: Collected essays on video games, learning and literacy. New York: Peter Lang.

Hemmi, A., Bayne, S. and Land, R. (2009). The appropriation and repurposing of social technologies in higher education. Journal of Computer Assisted Learning, 25 (1), pp. 19-30.

Herr, K. and Anderson, G.L. (2005). The action research dissertation. a guide for students and faculty. Thousand Oaks: Sage.

Illeris, K. (2003). Towards a contemporary and comprehensive theory of learning. International Journal of Lifelong Education, 22 (4), pp. 396-406.

Lankshear, C. and Knobel, M. (2006). Digital Literacy and Digital Literacies: Policy, Pedagogy and Research Considerations for Education. Nordic Journal of Digital Literacy, 1 (1), pp. 12-24.

Lankshear, C. and Knobel, M. (2007). Researching new literacies: Web 2.0 practices and insider perspectives. ELearning, 4 (3), pp. 224-240.

Lankshear, C. and Knobel, M. (2011). New literacies: Everyday practices and social learning. Third Edition. Maidenhead \& New York: Open University Press/McGraw-Hill.

Lau, J. (2006). Guidelines on information literacy for lifelong learning. Veracruz: IFLA.

Lave, J. and Wenger, E. (1991). Situated learning: Legitimate peripheral participation. Cambridge: Cambridge University Press.

Lewin, K. (1946). Action research and minority problems. Journal of Social Issues, 2 (4), pp. 34-46.

McIntyre, A. (2008). Participatory action research. Sage Publications, Inc.

McTaggart, R. (Ed.). (1997). Participatory action research: International contexts and consequences. Albany: State University of New York Press.

Machin-Mastromatteo, J.D. (2011a). Exploring users' information behavior in social networks: A contribution to the understanding of the use of social networks. Saarbrücken: Lambert Academic Publishing.

Machin-Mastromatteo, J.D. (2011b). Raamatukogunduskogemusi Venezuelast: Infopädevus ja infoteadus. Raamatukogu, 6, pp. 32 - 34.

Machin-Mastromatteo, J.D. (2012). The mutual shaping of social media, learning experiences, and literacies: The methods revisited, paper presented at the 4th International Conference on Qualitative and Quantitative Methods in Libraries (QQML 2012), 22-25 May 2012, Limerick, Ireland, available at: http://eprints.rclis.org/bitstream/10760/16885/6/qqm12012_machin_ver\%202.pdf (accessed 2 September 2012). 
Mikkelsen, H.B. (2001). Methods for development work and research: A guide for practitioners. Thousand Oaks: Sage.

Nonaka, I. and Takeuchi, H. (1995). The knowledge creating company: how Japanese companies create the dynamics of innovation. New York: Oxford University Press.

Polanyi, M. (1958). Personal knowledge. London: Routledge and Kegan Paul.

Shapiro, J.J. and Hughes, S.K. (1996). Information technology as a liberal art: enlightenment proposals for a new curriculum. Educom Review, 31 (2) pp. 31-35.

Smith, M.K. (2009). Communities of practice. infed.org The Encyclopedia of Informal Education. available at: http://www.infed.org/biblio/communities_of_practice.htm (accessed 2 September 2012).

Tuominen, K., Savolainen, R. and Talja, S. (2005). Information literacy as a sociotechnical practice. Library Quarterly, 75 (3), pp. 329-345.

Vygotsky, L.S. (1978). Mind in society: The development of higher mental processes. Cambridge, MA: Harvard University Press.

Virkus, S. (2003). Information literacy in Europe: A literature review. Information Research, 8 (4), pp. 8-4.

Wenger, E. (2006). Communities of practice: A brief introduction. Communities of Practice, available at: http://www.ewenger.com/theory/ (accessed 2 September 2012).

Whitehead, J. (1989). Creating a living educational theory from questions of the kind 'How do I improve my practice?' Cambridge Journal of Education, 19 (1): 137-53.

Whitehead, J. and McNiff, J. (2006). Action research: Living theory. London: Sage.

Zurkowski, P.G. (1974). The information service environment relationships and priorities. Washington: National Commission of Libraries and Information Science [USA]. 